\title{
Frequency of Hypoglycemia in Type 2 Diabetic Patients in Sample of Egyptian People in Clinic Based Study
}

\author{
Mohammed Saad Hamed, Ahmed Mohamed Bahaa El-Din, Bassem Murad Mostafa* \\ Department of Internal Medicine and Endocrinology Department, \\ Faculty of Medicine, Ain Shams University, Cairo, Egypt \\ *Corresponding Author: Bassem Murad Mostafa, Mobile: 00201144322070, Email: basemmurad44@med.asu.edu.eg,
}

\begin{abstract}
Background: Hypoglycemia is a serious medical emergency that must be recognised and treated as soon as possible to avoid organ and brain damage. Hypoglycemia is not a sickness in and of itself; it is a symptom of a more serious health problem, the significance of which is determined by its impact on brain function. There is always a risk of a proportional increase in the incidence of hypoglycemia with a growing incidence of diabetes and various modalities of intense blood glucose management.

Objective: We measured the frequency of hypoglycemic attacks in type 2 diabetic patients (T2DM) in clinic-based study and correlate the attacks of hypoglycemia with treatment regimens and duration of the diabetes mellitus (DM).

Patients and Methods: Copies of pre-tested questionnaire were administered directly to 1000 patients with T2DM at the study site. This questionnaire was previously published as a part of the Workgroup of the American Diabetes Association and The Endocrine Society (ADA) on 2013. After translating it into public traditional Egyptian Arabic language. Results: Our main finding was that for people with T2DM the incidence of hypoglycemia was 36\% (360 out of 1000 patients). $26.39 \%$ (95 out of 360 patients) were on oral hypoglycemic drugs compared to $71.94 \%$ (259 from 360 patients) on insulin. Hypoglycemia was $48.42 \%$ (46 out of 95 patients) in diabetic patients having diabetes for more than five years and on oral hypoglycemic drugs, compared to $76.83 \%$ (199 out of 259 patients) in diabetic patients on insulin. Conclusion: Hypoglycemia is common in T2DM (36\%). It is a significant complication of diabetes therapy and although mild hypoglycemia causes unpleasant symptoms and disrupts patients' daily activities, severe hypoglycemia can result in coma, seizures, and death.
\end{abstract}

Keywords: Diabetes duration, Hypoglycemia, Impaired awareness of hypoglycemia (IAH), Type 2 diabetes mellitus (T2DM).

\section{INTRODUCTION}

Hypoglycemia is defined as any episode of unusually low plasma glucose concentration (with or without symptoms) that puts a person at risk ${ }^{(1)}$. A plasma glucose level of less than $70 \mathrm{mg} / \mathrm{dL}$ (3.9 $\mathrm{mmol} / \mathrm{L}$ ) is usually considered hypoglycemia ${ }^{(2)}$.

Inhibition of endogenous insulin secretion and stimulation of glucagon, catecholamines (norepinephrine, epinephrine), cortisol, and growth hormone secretion are all part of the counter-regulatory response to hypoglycemia, which all work together to stimulate hepatic glucose production and cut down glucose utilisation in peripheral tissues, raising plasma glucose levels ${ }^{(3)}$.

Whipple's triad, which includes symptoms associated with hypoglycemia, a low plasma glucose concentration detected by an accurate method, and relief of symptoms when the plasma glucose level is elevated, can be used to diagnose hypoglycemia ${ }^{(4)}$.

The pathophysiology of glucose counter regulation, specifically the rate of beta cell failure and the resulting rate of alpha cell failure, is a function of the difference in the incidence of iatrogenic hypoglycemia (relatively high throughout the course of type 1 diabetes but progressing from relatively low to relatively high over the course of type 2 diabetes) ${ }^{(5)}$. There is always a risk of a proportional increase in the incidence of hypoglycemia with a growing incidence of diabetes and various modalities of intense blood glucose management ${ }^{(6)}$.

The overarching goal of managing type 2 diabetes is to achieve and maintain blood glucose control while lowering the risk of long-term complications. Many studies have demonstrated that current diabetes care with strict glycemic control can reduce, postpone, or even avoid the development of chronic problems. This aggressive diabetic therapy, however, may be linked to a higher risk of hypoglycemia ${ }^{(7)}$.

The aim of the present study was measure the frequency of hypoglycemic attacks in type 2 diabetic patients in clinic-based study and to correlate the attacks of hypoglycemia with treatment regimens and duration of the diabetes.

\section{PATIENTS AND METHODS}

Through convenience sampling from outpatient clinics of Ain Shams University Hospitals, 1000 patients with type 2 diabetes were chosen in the duration from September 2017 to June 2018.

Copies of pre-tested questionnaire were administered directly to 1000 patients with type 2 diabetes at the study site. This questionnaire was previously published as a part of the Workgroup of the American Diabetes Association and The Endocrine Society (8). After translating it into public traditional Egyptian Arabic language to facilitate the mission for the interviewer. 
The patient questionnaire investigated the following aspects: sociodemographic and clinical characteristics, including age, gender, school education, employment status, marital status, diabetes duration, medical treatment for diabetes, adherence to treatment, hypoglycemic symptoms and frequency of hypoglycemia occurrence.

Hypoglycemia is defined as any episode of unusually low plasma glucose concentration (with or without symptoms) that puts a person at risk ${ }^{(1)}$. A plasma glucose level of less than $70 \mathrm{mg} / \mathrm{dL}(3.9 \mathrm{mmol} / \mathrm{L})$ is usually considered hypoglycemia ${ }^{(2)}$.

Inhibition of endogenous insulin secretion and stimulation of glucagon, catecholamines (norepinephrine, epinephrine), cortisol, and growth hormone secretion are all part of the counter-regulatory response to hypoglycemia, which all work together to stimulate hepatic glucose production and cut down glucose utilisation in peripheral tissues, raising plasma glucose levels ${ }^{(3)}$.

Whipple's triad, which includes symptoms associated with hypoglycemia, a low plasma glucose concentration detected by an accurate method, and relief of symptoms when the plasma glucose level is elevated, can be used to diagnose hypoglycemia ${ }^{(4)}$.

The pathophysiology of glucose counter regulation, specifically the rate of beta cell failure and the resulting rate of alpha cell failure, is a function of the difference in the incidence of iatrogenic hypoglycemia (relatively high throughout the course of type 1 diabetes but progressing from relatively low to relatively high over the course of type 2 diabetes) ${ }^{(5)}$. There is always a risk of a proportional increase in the incidence of hypoglycemia with a growing incidence of diabetes and various modalities of intense blood glucose management ${ }^{\left({ }^{6}\right)}$. The overarching goal of managing type 2 diabetes is to achieve and maintain blood glucose control while lowering the risk of long-term complications. Many studies have demonstrated that current diabetes care with strict glycemic control can reduce, postpone, or even avoid the development of chronic problems. This aggressive diabetic therapy, however, may be linked to a higher risk of hypoglycemia ${ }^{(7)}$.

The aim of the present study was measure the frequency of hypoglycemic attacks in type 2 diabetic patients in clinic-based study and to correlate the attacks of hypoglycemia with treatment regimens and duration of the diabetes.

\section{PATIENTS AND METHODS}

Through convenience sampling from outpatient clinics of Ain Shams University Hospitals, 1000 patients with type 2 diabetes were chosen in the duration from September 2017 to June 2018.

Copies of pre-tested questionnaire were administered directly to 1000 patients with type 2 diabetes at the study site. This questionnaire was previously published as a part of the Workgroup of the American Diabetes
Association and The Endocrine Society ${ }^{(8)}$. After translating it into public traditional Egyptian Arabic language to facilitate the mission for the interviewer. The patient questionnaire investigated the following aspects: sociodemographic and clinical characteristics, including age, gender, school education, employment status, marital status, diabetes duration, medical treatment for diabetes, adherence to treatment, hypoglycemic symptoms and frequency of hypoglycemia occurrence.

\section{Ethical consent:}

An approval of the study was obtained from Ain Shams University Academic and Ethical Committee. Every patient signed an informed written consent for acceptance of the study. This work has been carried out in accordance with The Code of Ethics of the World Medical Association (Declaration of Helsinki) for studies involving humans.

\section{Statistical analysis:}

The collected data were coded, processed and analyzed using the SPSS (Statistical Package for the Social Sciences) version 22 for Windows ${ }^{\circledR}$ (IBM SPSS Inc, Chicago, IL, USA). Data were represented as frequencies and relative percentages and were compared by Chi square test $\left(\chi^{2}\right)$. P value $<0.05$ was considered significant.

\section{RESULTS}

Frequency of hypoglycemic attacks among diabetic patients is $36 \%$ (Table 1 and figure 1)

Table (1): Frequency of hypoglycemic attacks among diabetic patients

\begin{tabular}{|c|c|c|}
\hline \multicolumn{3}{|c|}{ Hypoglycemic attacks } \\
\hline Yes & N & $\%$ \\
\hline No & 640 & 36.00 \\
\hline Total & 1000 & 64.00 \\
\hline
\end{tabular}

Mild to Moderate (tarnishing of the eyes, tongue numbness, tremors, difficulty concentrating, drowsiness, some interruption of activities, and no assistance needed to manage symptoms). Severe (unconsciousness or fainting, needing the assistance of others to manage symptoms).

Table 2 shows that the frequency of severe hypoglycemia was $15.28 \%$

Table (2): Percentages of types of hypoglycemia

\begin{tabular}{|c|c|c|}
\hline \multicolumn{3}{|c|}{ Types of hypoglycemia } \\
\hline & $\mathbf{N}$ & $\mathbf{\%}$ \\
\hline Mild to Moderate & 320 & 86.11 \\
\hline Severe & 55 & 15.28 \\
\hline
\end{tabular}

Table 3 shows that odds ratio for patients on insulin was high $(\mathrm{OR}>1)$. 
Table (3): Correlation between diabetic patients on oral hypoglycemic drugs and insulin therapy as regard occurrence of hypoglycemia

\begin{tabular}{|c|c|c|c|}
\hline & Odds ratio & 95\% CI & P-value \\
\hline Oral tablets & 0.343 & $0.259-0.455$ & $<0.001^{*}$ \\
\hline Insulin & 2.952 & $2.237-3.895$ & $<0.001^{*}$ \\
\hline Both & 0.706 & $0.272-1.837$ & 0.476 \\
\hline
\end{tabular}

Table 4 shows that there was a highly statistically significant difference between diabetic patients on insulin and long duration of diabetes.

Table (4): Comparison between different modalities of treatment of diabetes as regard duration of diabetes and occurrence of hypoglycemia

\begin{tabular}{|c|c|c|c|c|c|c|c|c|c|}
\hline \multirow{3}{*}{$\begin{array}{l}\text { Treatment } \\
\text { Now }\end{array}$} & \multirow{3}{*}{$\begin{array}{c}\text { Duration } \\
\text { of diabetes }\end{array}$} & \multicolumn{6}{|c|}{ Hypoglycemic attacks } & \multirow{2}{*}{\multicolumn{2}{|c|}{ Chi-Square }} \\
\hline & & \multicolumn{2}{|c|}{ Yes } & \multicolumn{2}{|c|}{ No } & \multicolumn{2}{|c|}{ Total } & & \\
\hline & & $\mathbf{N}$ & $\%$ & $\mathbf{N}$ & $\%$ & $\mathbf{N}$ & $\%$ & $\mathbf{X}^{2}$ & P-Value \\
\hline \multirow{3}{*}{$\begin{array}{l}\text { Oral } \\
\text { Tablets }\end{array}$} & $\begin{array}{l}\text { Less than } \\
\text { one year }\end{array}$ & 9 & 9.47 & 46 & 14.07 & 55 & 13.03 & \multirow{3}{*}{4.476} & \multirow{3}{*}{$0.034 *$} \\
\hline & $\begin{array}{c}\text { From one } \\
\text { year to five years }\end{array}$ & 40 & 42.11 & 162 & 49.54 & 202 & 47.87 & & \\
\hline & $\begin{array}{l}\text { More than } \\
\text { five years }\end{array}$ & 46 & 48.42 & 119 & 36.39 & 165 & 39.10 & & \\
\hline \multirow{3}{*}{ Insulin } & $\begin{array}{l}\text { Less than } \\
\text { one year }\end{array}$ & 6 & 2.32 & 37 & 12.42 & 43 & 7.72 & \multirow{3}{*}{19.846} & \multirow{3}{*}{$<0.001 *$} \\
\hline & $\begin{array}{l}\text { From one year } \\
\text { to five years }\end{array}$ & 54 & 20.85 & 55 & 18.46 & 109 & 19.57 & & \\
\hline & $\begin{array}{l}\text { More than } \\
\text { five years }\end{array}$ & 199 & 76.83 & 206 & 69.13 & 405 & 72.71 & & \\
\hline \multirow{2}{*}{ Both } & $\begin{array}{l}\text { From one year } \\
\text { to five years }\end{array}$ & 0 & 0.00 & 4 & 26.67 & 4 & 19.05 & \multirow{2}{*}{1.976} & \multirow{2}{*}{0.160} \\
\hline & $\begin{array}{l}\text { More than } \\
\text { five years }\end{array}$ & 6 & 100.00 & 11 & 73.33 & 17 & 80.95 & & \\
\hline
\end{tabular}

Figure 1 shows that $23.61 \%$ of patients could feel symptoms of hypoglycemia as regard to The Pedersen-Bjergaard method.
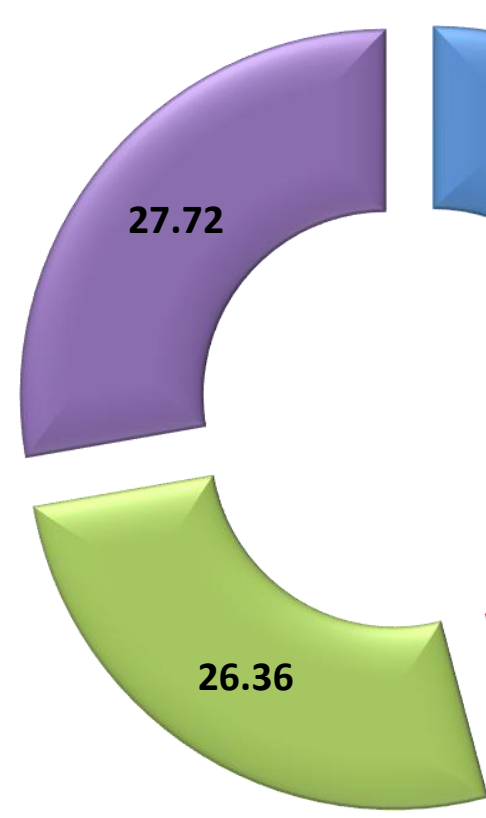

Figure (1): Awareness of hypoglycemic symptoms.

\subsection{2}

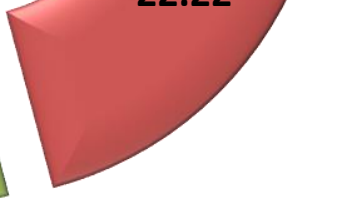

Dalways

口usually

a sometimes

口never

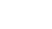


Table (5): The frequency of occurrence of hypoglycemia in different age groups of diabetic patients

\begin{tabular}{|c|c|c|c|c|c|c|}
\hline \multirow{2}{*}{ Age groups } & \multicolumn{3}{|c|}{ Hypoglycemic attacks } \\
\cline { 2 - 7 } & \multicolumn{2}{|c|}{ Yes } & \multicolumn{2}{c|}{ No } & \multicolumn{2}{c|}{ Total } \\
\cline { 2 - 7 } & $\mathbf{N}$ & $\mathbf{\%}$ & $\mathbf{N}$ & $\mathbf{\%}$ & $\mathbf{2}$ \\
\hline <40 Years & 60 & 16.67 & 150 & 23.44 & 210 & 21.00 \\
\hline 41-60 Years & 200 & 55.56 & 353 & 55.16 & 553 & 55.30 \\
\hline$>\mathbf{6 0}$ Years & 100 & 27.78 & 137 & 21.41 & 237 & 23.70 \\
\hline Total & 360 & 100.00 & 640 & 100.00 & 1000 & 100.00 \\
\hline
\end{tabular}

Table 6 shows that there was a high statistically significant difference between the occurrence of hypoglycemic episodes and the presence of other diseases other than diabetes in patients with diabetes.

Table (6): Comparison between diabetic patients who had other diseases other than diabetes and those who had not other diseases as regard occurrence of hypoglycemic episodes

\begin{tabular}{|c|c|c|c|c|c|c|c|c|}
\hline \multirow{3}{*}{ Other diseases } & \multicolumn{6}{|c|}{ Hypoglycemic attacks } & \multicolumn{2}{|c|}{ Chi-Square } \\
\hline & \multicolumn{2}{|c|}{ Yes } & \multicolumn{2}{|c|}{ No } & \multicolumn{2}{|c|}{ Total } & & \\
\hline & $\mathbf{N}$ & $\%$ & $\mathbf{N}$ & $\%$ & $\mathbf{N}$ & $\%$ & $X^{2}$ & P-value \\
\hline Yes & 227 & 63.06 & 284 & 44.38 & 511 & 51.10 & \multirow{3}{*}{32.176} & \multirow{3}{*}{$<0.001 *$} \\
\hline No & 133 & 36.94 & 356 & 55.63 & 489 & 48.90 & & \\
\hline Total & 360 & 100.00 & 640 & 100.00 & 1000 & 100.00 & & \\
\hline
\end{tabular}

Table 7 shows that there was no significant difference between patients taking snacks between main meals and thos who were not taking as regard occurrence of hypoglycemia.

Table (7): Comparison between diabetic patients who took snacks between main meals and those who did not take snacks as regard occurrence of hypoglycemia

\begin{tabular}{|c|c|c|c|c|c|c|c|c|}
\hline \multirow{3}{*}{ Snacks } & \multicolumn{6}{|c|}{ Hypoglycemic attacks } & \multicolumn{2}{|c|}{ Chi-Square } \\
\hline & \multicolumn{2}{|c|}{ Yes } & \multicolumn{2}{|c|}{ No } & \multicolumn{2}{|c|}{ Total } & & \\
\hline & $\mathbf{N}$ & $\%$ & $\mathbf{N}$ & $\%$ & $\mathbf{N}$ & $\%$ & $\mathbf{X}^{2}$ & P-value \\
\hline Yes & 152 & 42.22 & 248 & 38.75 & 400 & 40.00 & \multirow{3}{*}{1.157} & \multirow{3}{*}{0.282} \\
\hline No & 208 & 57.78 & 392 & 61.25 & 600 & 60.00 & & \\
\hline Total & 360 & 100.00 & 640 & 100.00 & 1000 & 100.00 & & \\
\hline
\end{tabular}

\section{DISCUSSION}

Hypoglycemia can be a dangerous condition that happen in people with diabetes who take medicines that increase insulin levels in the body.

In our study, we examined the frequencies of hypoglycemia in people with diabetes with regard to treatment modality (oral or insulin) and in the event of the duration of diabetes.

Our study was conducted on 1000 Egyptian type two diabetic patients randomly selected from outpatient clinics of Ain Shams University Hospitals, age 18-80 years old with mean age 51 (58\% female [580], 42\% male [420]). Among these individuals 297 (29.7\%) were employed, $89 \%$ (890) were married, 37.3 (373\%) were illiterate.

Patients on oral hypoglycemic drugs were $42.2 \%$ (422 patients out of 1000 patients), patients on insulin were $55.7 \%$ (557 patients out of 1000 patients), and patients on both oral and insulin were $2.1 \%$ (21 patients out of 1000).

In diabetic patients having diabetes for more than five years and on oral hypoglycemic drugs, hypoglycemia was $48.42 \%$ (46 patients out of 95 patients) compared to $76.83 \%$ (199 patients out of 259 patients) in diabetic patients on insulin. Our study shows that there was a statistically significant difference between diabetic patients on oral hypoglycemic and long duration of diabetes and it also shows that there was a highly statistically significant correlation between diabetic patients on insulin and long duration of diabetes, and this is in consistent with The UK Hypoglycemia Study, which found that patients with longer duration of diabetes ( $>15$ years) experienced higher rates of severe hypoglycemia than those with smaller duration ( $>5$ years) $(46 \%$ vs. $22 \%)$.

Also we found that mild to moderate hypoglycemia was $86.11 \%$ (320 patients out of 360 patients) while severe hypoglycemia was $15.28 \%$ (55 patients out of 360 patients) about 15 patients who complained of severe hypoglycemia reported attacks of mild to moderate hypoglycemia and this in consistent with Henderson et $\boldsymbol{a l} .{ }^{(4)}$ A retrospective study has reported an annual prevalence of severe hypoglycemia in insulin-treated type 2 diabetes of $15 \%$, however in, Gehlaut $\boldsymbol{e t}$ al. (9) severity of hypoglycemia was distributed as follows: $21 \%$ (11 out of 53) severe hypoglycemia, $51 \%$ (27 out of 53) mild, and $28.3 \%$ (15 out of 53) moderate. The study revealed that $23.61 \%$ of 
patients could always predict hypoglycemia. $22.22 \%$ of patients could usually predict hypoglycemia. $26.36 \%$ of patients could sometimes predict hypoglycemia. $27.72 \%$ of patients never predict hypoglycemia. According to the Pedersen-Bjergaard, Prevalence of (IAH) impaired awareness of hypoglycemia is $49.94 \%$ and unawareness is $27.72 \%$. However Büyükkaya $\boldsymbol{e t}$ al. ${ }^{(10)}$ in their study of 187 patients with type 2 diabetes in Turkey, $83.4 \%$ had impaired awareness of their hypoglycemia.

Our study shows that there was a high statistically significant difference between the occurrence of hypoglycemic episodes and the presence of other diseases other than diabetes in patients with diabetes. Also our study shows that there was no significant difference between diabetic patients who took snacks between main meals and those who did not take snacks as regard occurrence of hypoglycemia.

\section{CONCLUSION}

The incidence of hypoglycemia was 36\% (360 patients from 1000 patients). This finding reiterates the importance of enquiring and educating every diabetic patient about hypoglycemic episodes during every health visit.

There was a highly statistically significant correlation between diabetic patients on insulin and long duration of diabetes. Also there was a statistically significant difference between diabetic patients on oral hypoglycemic and long duration of diabetes.

There was a high statistically significant difference between the occurrence of hypoglycemic episodes and the presence of other diseases other than diabetes in patients with diabetes.

Prevalence of (IAH) impaired awareness of hypoglycemia was $49.94 \%$ and unawareness is $27.72 \%$.

Financial support and sponsorship: Nil.

Conflict of interest: Nil.

\section{REFERENCES}

1. American Diabetes Association (2005): Workgroup on hypoglycemia defining and reporting hypoglycemia in diabetes. Diabetes Care, 28(5):1245-9.

2. Desouza C, Salazar H, Cheong B et al. (2003): Association of hypoglycemia and cardiac ischemia: a study based on continuous monitoring. Diabetes Care, 26:1485-1489.

3. de Galan B, Schouwenberg B, Tack C et al. (2006): Pathophysiology and management of recurrent hypoglycaemia and hypoglycaemia unawareness in diabetes. Neth J Med., 64:269-279.

4. Henderson J, Allen K, Deary I et al. (2003): Hypoglycemia in insulin-treated type 2 diabetes: frequency, symptoms and impaired awareness. Diabet Med., 20(12):1016-1021.

5. Cryer $P$ (2016): Hypoglycemia in diabetes: Pathophysiology, prevalence, and prevention, $3^{\text {rd }}$, American Diabetes Association, Alexandria, VA. Hypoglycemia in Diabetes. https://www.wolterskluwer.com/en/solutions/ovid/hypo glycemia-in-diabetes-pathophysiology-prevalence-andprevention-14627

6. Holstein A, Egberts E (2003): Risk of hypoglycaemia with oral antidiabetic agents in patients with Type 2 diabetes. Exp Clin Endocrinol Diabetes, 111:405-414.

7. Donnelly L, Morris A, Frier B et al. (2005): Frequency and predictors of hypoglycaemia in type 1 and insulintreated type 2 diabetes: A population-based study. Diabet Med., 22:749-53.

8. Seaquist E, Anderson J, Childs B et al. (2013): Hypoglycemia and diabetes: a report of a workgroup of the American Diabetes Association and the Endocrine Society. Diabetes Care, 36(5):1384-95.

9. Gehlaut R, Dogbey G, Schwartz F et al. (2015): Hypoglycemia in type 2 diabetes--more common than you think: A continuous glucose monitoring study. J Diabetes Sci Technol., 2015 9(5): 999-1005.

10. Büyükkaya B, Sürücü A, Koşar C (2016): Selfreported frequency, severity of, and awareness of hypoglycemia in type 2 diabetes patients in Turkey. Peer J., 4: 2700-2705. 